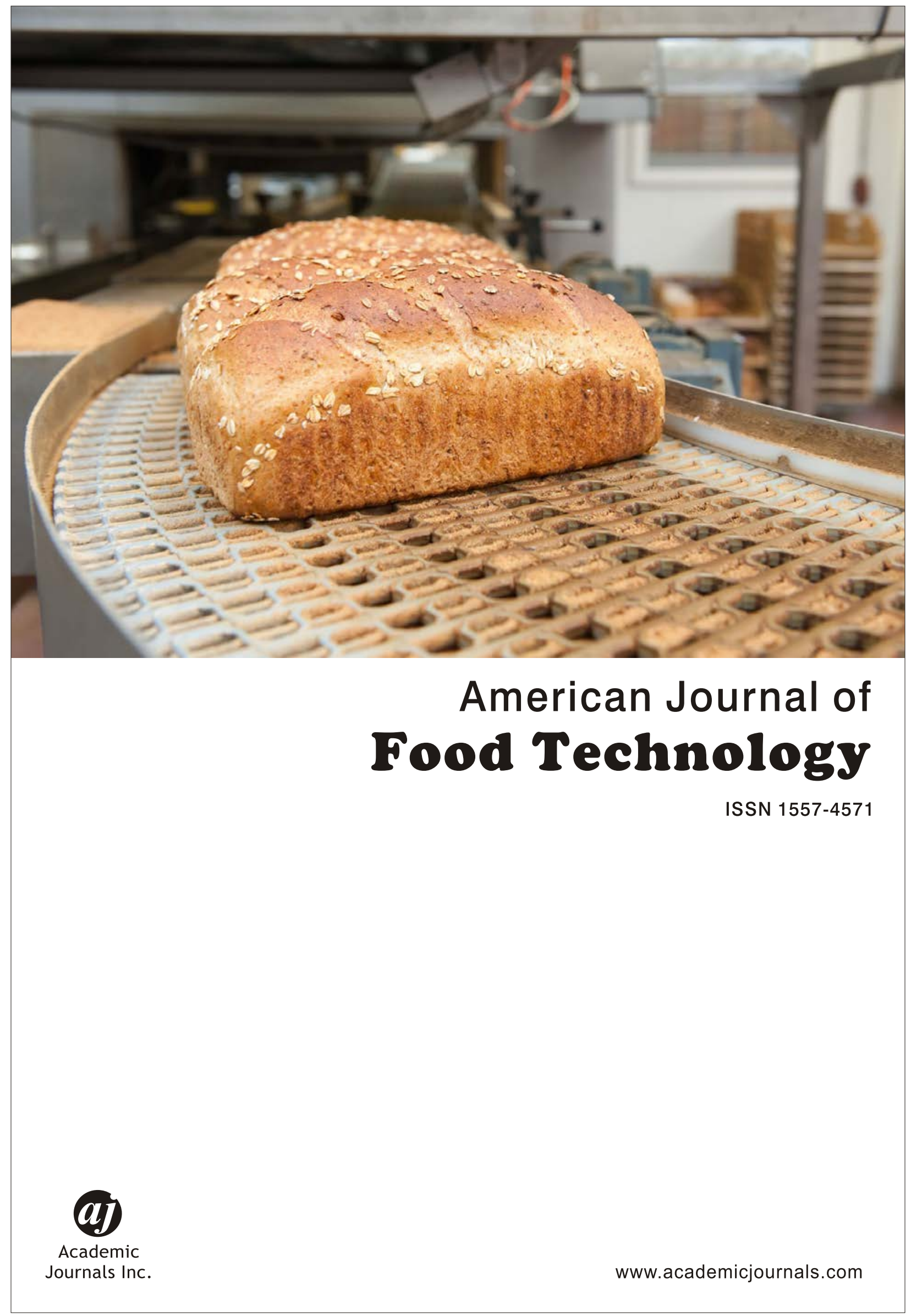




\title{
Bioactive Compounds Extracted from the Pinto Bean Using Membrane Technology Inhibits Biofilm Formation of Listeria monocytogenes
}

\author{
${ }^{1}$ Yong Jae Lee, ${ }^{2}$ Eunsoo Yoo, ${ }^{2}$ Dongin Kim and ${ }^{3}$ Seok Hoon Hong \\ ${ }^{1}$ Department of Nutrition and Food Science, Texas A and M University, College Station, TX, 77843, USA \\ ${ }^{2}$ Department of Pharmaceutical Sciences, Rangel College of Pharmacy, Texas A and M University, College Station, TX, 77843, USA \\ ${ }^{3}$ Department of Chemical and Biological Engineering, Illinois Institute of Technology, Chicago, IL 60616, USA
}

\section{Abstract}

Background and Objective: Pinto beans contain significant amounts of phytochemicals such as lectins and polyphenols. In this study, two bioactive-rich fractions from the pinto bean were extracted and isolated using acid treatment and membrane-based separation. Moreover, bioactive compounds from pinto bean were investigated to see whether it is effective in repressing biofilm formation of Listeria monocytogenes and ovarian cancer cell. Materials and Methods: The lectin- and polyphenol-rich fraction were extracted from the pinto bean using acid treatment and membrane technology, which are a simple, inexpensive and high yield promising method has not been reported previously. Two fractions were applied to inhibit the Listeria biofilm formation and ovarian cancer cell viability. Results: The lectin-rich fraction from ultrafiltration retentate (UFRT) was able to significantly reduce L. monocytogenes biofilm formation at $96.66 \%$ at $1,000 \mu \mathrm{g} \mathrm{mL}{ }^{-1}$ followed by $81.16 \%$ at $100 \mu \mathrm{g} \mathrm{mL}^{-1}$ dosing concentrations. The polyphenol-rich fraction from nanofiltration retentate (NFRT) was not shown to significantly reduce the biofilm formation as well as the ovarian cancer cell viability which may be due to the low polyphenol activity and high oligosaccharides content. Conclusion: These results support that ultrafiltration is able to separate the lectin-rich fraction from pinto beans which can be used as a promising Listerial anti-biofilm agent to the food industry.

Key words: Lectin, polyphenol, pinto bean, membrane technology, Listeria monocytogenes biofilm, ovarian cancer

Citation: Yong Jae Lee, Eunsoo Yoo, Dongin Kim and Seok Hoon Hong, 2019. Bioactive compounds extracted from the pinto bean using membrane technology inhibits biofilm formation of Listeria monocytogenes. Am. J. Food Technol., 14: 11-18.

Corresponding Author: Yong Jae Lee, Department of Nutrition and Food Science, Texas A and M University, College Station, TX, 77843, USA

Tel: (+1) 8642762363

Copyright: @ 2019 Yong Jae Lee etal. This is an open access article distributed under the terms of the creative commons attribution License, which permits unrestricted use, distribution and reproduction in any medium, provided the original author and source are credited.

Competing Interest: The authors have declared that no competing interest exists. 


\section{INTRODUCTION}

Pinto beans (Phaseolus vulgaris) has been considered as an underutilized legume containing high amounts of phytochemicals such as lectins and polyphenols as well as high nutritional value'. It has been reported that phytochemicals isolated from pinto beans possess anti-fungal, anti-bacterial, anti-diabetic and anti-tumor activities ${ }^{2-5}$. Biological activities of lectin from pinto beans have been studied to fight against bacteria, fungi, viruses and tumor during the last decades².

Lectins are natural substances that have at least one binding site without immunological characteristics or catalytic function. It is classified as a carbohydrate-binding protein which binds with mono and oligosaccharides ${ }^{5,6}$ and it is distinct from enzymes and antibodies ${ }^{7}$. Its anti-biofilm mechanism is not clearly identified but lectin can bind on the bacterial surface and inhibit initial attachment of bacteria on the solid surfaces since the cell wall of microbes contains abundant lipopolysaccharides and glycoprotein $\mathrm{s}^{8,9}$. The lectins from pinto beans are known as erythroagglutinin (PHA-E) and leucoagglutinin (PHA-L) which have molecular weights in the range $e^{5,6}$ of $31-34 \mathrm{kDa}$ and are composed of $2.5-5.0 \%$ of pinto bean protein ${ }^{2,10}$. Polyphenols $(500-4,000 \mathrm{Da}$ ) are another major phytochemical in pinto beans that are largely found in natural materials and have an anti-oxidants effect involved in the prevention of cancer and metabolic syndromes ${ }^{11,12}$ as well as anti-diabetic, anti-obesity, anti-inflammatory and anti-microbial ${ }^{11,13}$. Pinto beans contain plenty of polyphenols such as flavonoids, anthocyanins and tannins ${ }^{14,15}$ that are composed of about $11 \%$ of the whole pin to bean seed ${ }^{16}$.

Listeria monocytogenes is a food borne pathogen that is able to cause a severe illness called listeriosis ${ }^{17,18}$. Biofilm formation of L. monocytogenes results in serious threats to food safety and economic loss in the related industry ${ }^{19}$. Moreover, Listeria cells embedded in biofilms are more resistant to antibiotics and disinfectants than the planktonic cells due to their robustness in structure and biofilm-specific physiology distinct from the planktonic ones ${ }^{20-22}$. Therefore, it is important to explore alternative natural anti-bacterial agents that can effectively inhibit biofilm formation of L. monocytogenes.

The aim of this study was to extract and isolate two bioactive-rich fractions from the pinto bean using acid treatment and membrane-based separation method which has not been reported previously. This method has several advantages including a low-cost, an environmentally friendly approach and a scalable isolation of bioactive compounds, especially lectins. Moreover, extracted bioactive compounds from pinto bean were investigated to see whether it is effective in repressing biofilm formation of $L$. monocytogenes and ovarian cancer cell.

\section{MATERIALS AND METHODS}

Materials: The pinto beans used in this study were obtained from a local store. It was ground using a commercial coffee grinder, then sieved with 40 mesh screens.

Extraction and separation of bioactive compounds from pinto bean powder bioactive compounds from pinto bean powder were produced with the acid treatment followed by membrane technology. The schematic procedure is shown in Fig. 1. The $\mathrm{pH}$ of pinto bean powder solutions (1:10 ratio) was adjusted and maintained to 4.3 using $85 \%$ phosphoric acid solutions at room temperature for $2 \mathrm{~h}$. The acid treated slurries were centrifuged at 4,700 rpm for $30 \mathrm{~min}$ (Sorvall RC-5C Plus Centrifuge and SLA-1500 rotor, Kendro Laboratory Products, Asheville, NC, USA). The centrifuged wet cake was rinsed three times with acid solutions (85\% phosphoric acid). The supernatants were used for further bioactive compounds separation with ultrafiltration and nanofiltration. Ultrafiltration retentate (UFRT) was prepared with filtration for the supernatant from the acid slurries with a spiral wound composite cross flow system (5 kDa MWCO, Synder, Vacaville, CA). The permeated liquid was filtered using a nanofiltration system (Synder, Vacaville, CA), which was 150-300 Da MWCO. The water of UFRT and NFRT solutions were evaporated using rotavapor and freeze-dried to obtain high purity bioactive compounds.

Proximate compositional analysis moisture was measured by oven hot air-drying method at $120^{\circ} \mathrm{C}$ for $24 \mathrm{~h}$ incubation. The fats and lipids were measured by Soxhlet extraction, ash was measured by muffle furnace at $550^{\circ} \mathrm{C}$ for $4 \mathrm{~h}$ and dietary fiber content was determined in triplicate by the $\mathrm{AOAC}^{23}$ method. Protein content was analyzed by the high-temperature combustion process. The total carbohydrates and others were calculated by difference.

Biofilm formation assay using crystal violet staining For Listeria biofilm experiment, the freeze-dried UFRT and NFRT powder were dissolved in S30 buffer composed of $10 \mathrm{mM}$ Tris-acetate $\mathrm{pH}$ 8.2, $14 \mathrm{mM}$ magnesium acetate, $60 \mathrm{mM}$ potassium acetate to make a stock solution. The biofilm assay was conducted in 96-well polystyrene plates (Costar 3370, Corning Incorporated, Corning, NY) using 0.1\% crystal violet staining ${ }^{24}$. Listeria monocytogenes serotype $4 \mathrm{~b}$ (ATCC 19115) was used for biofilm experiment. Bacterial cultures were grown overnight in Luria-Bertani (LB) at 220 rpm 


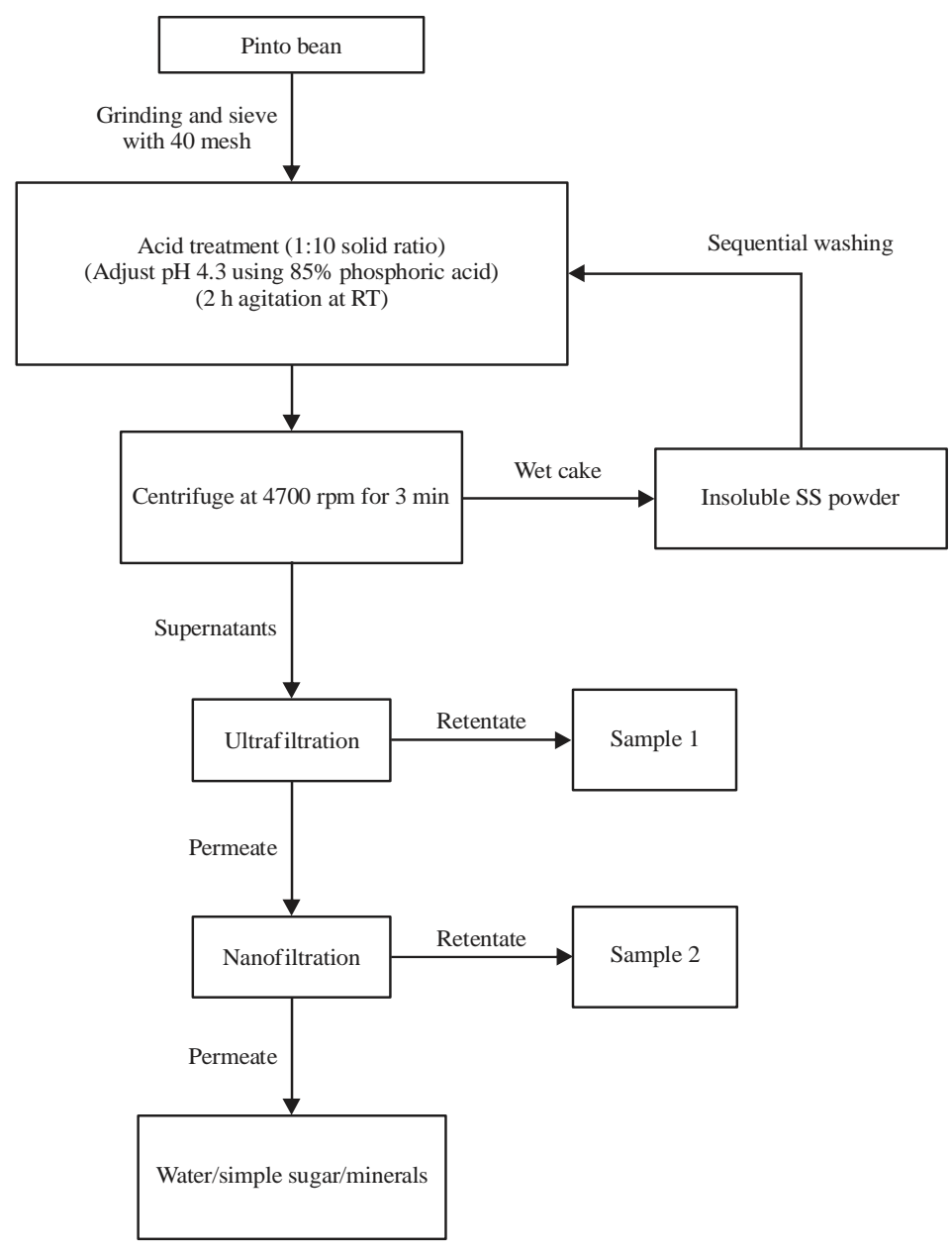

Fig. 1: Bioactive compounds extraction from the pinto bean using acid treatment and membrane technology

at $37^{\circ} \mathrm{C}$ were adjusted to 0.05 of the optical density at $600 \mathrm{~nm}$ with M9 minimal medium supplemented with $0.4 \%$ glucose (M9G) (Cold Spring Harbor Laboratory). For biofilm formation, $300 \mathrm{~mL}$ of the diluted culture was added into the 96-well plate with UFRT and NFRT (final concentration 100 and $1,000 \mathrm{mg} \mathrm{mL}^{-1}$ ). Biofilm plate was incubated at $37^{\circ} \mathrm{C}$ for $24 \mathrm{~h}$ without shaking. Cell growth $\left(\mathrm{OD}_{600 \mathrm{~nm}}\right)$ was measured using Synergy HTX plate reader (Biotek, Winooski, VT) and biofilms were washed three times with $\mathrm{dH}_{2} \mathrm{O}$. Then $300 \mathrm{~mL}$ of $0.1 \%$ $(\mathrm{w} / \mathrm{v})$ crystal violet was added into the biofilm plate and incubated for $20 \mathrm{~min}$ at room temperature. The crystal violet dye stains both the air-liquid interface and bottom liquid-solid interface biofilm ${ }^{25}$. Biofilm cells stained with crystal violet were resuspended in $95 \%$ ethanol. The total biofilm formation was measured at $540 \mathrm{~nm}$. The Listeria biofilm level was normalized by dividing the total biofilms $\left(\mathrm{OD}_{540 \mathrm{~nm}}\right)$ by cell growth $\left(\mathrm{OD}_{600 \mathrm{~nm}}\right)$.

Ovarian cancer cell viability test A2780 cell at $5 \times 10^{4}$ cells $\mathrm{cm}^{-2}$ were seed in a 96 well plate and cultured until $100 \%$ confluent under standard conditions at $37^{\circ} \mathrm{C}$ with $5 \% \mathrm{CO}_{2}$ and $100 \%$ humidity. The stock solutions of fractionated pinto bean samples were diluted to $0.001,0.1,1,10,100$ and $1000 \mu \mathrm{g} \mathrm{mL} \mathrm{m}^{-1}$ in cell medium (RPMI-1640). After $24 \mathrm{~h}$ incubation, $10 \mu \mathrm{L}$ of the cell counting kit-8 (CCK-8; Enzo Life Science, Lausen, Switzerland) solution was added into appropriate wells. After $1 \mathrm{~h}$ incubation, the absorbance was measured at $450 \mathrm{~nm}$ using a SpectraMax M3 microplate reader (Molecular Devices Inc., Sunnyvale, CA).

Statistical Analysis: All treatments in this study were conducted in triplicate and a 95\% confidence level significance was applied for data analysis. Measurements were analyzed by a one-way analysis of variance (ANOVA) using GLM (General Linear Model) procedure in SAS 9.1 software (SAS Institute INC., Cary, NC). The statistically significant difference between the averages in treatments was accessed by Duncan's multiple range tests. Differences were considered significant for $p$-values lower than 0.05 . 


\section{RESULTS}

Extraction and separation of bioactive compounds using an acid treatment and membrane filtration. Table 1 shows the mass balance of each fractionation during the process. The $99 \%$ of overall mass was recovered through the process. By acid treatment, $37 \%$ solid was solubilized from pinto beans which contain soluble carbohydrates, lectins and polyphenols while $62 \%$ solid was insoluble materials in acid condition ( $\mathrm{pH} 4.3$ ) such as aggregated proteins and fibers. About $47.22 \%$ of the lectin-rich fraction from UFRT and about $11.11 \%$ of the polyphenol-rich fraction from NFRT were produced from centrifuged supernatants. Table 2 shows the results of the proximate compositional analysis. Pinto bean powder contained $23.50 \%$ protein, $71.45 \%$ carbohydrates and others, which include simple sugars, dietary fibers and polyphenols.
With a centrifuge, the protein content increased to $31.75 \%$ in the centrifuged wet cake, while the dietary fiber content was increased and the simple sugar content was decreased from pinto bean powder. The UFRT contained $59.92 \%$ protein and $36.23 \%$ carbohydrates and others. The NFRT contained $2.12 \%$ protein and carbohydrates and others contents were significantly higher (94.32\%) than others (protein, fat and ash). The NFPE contained $51.65 \%$ simple sugars.

The activity of UFRT and NFRT in inhibiting L. monocytogenes biofilm formation and the ovarian cancer cell. The Listeria anti-biofilm assay (Fig. 2) showed that lectin-rich fraction from UFRT was able to significantly reduce $(p<0.05)$ the biofilm formation by 100 and $1,000 \mu \mathrm{g} \mathrm{mL}$ dosing rate. The best results were found for L. monocytogenes biofilm, with a reduction of $96.66 \%$ in biofilm formation at $1,000 \mu \mathrm{gL}^{-1}$ UFRT followed by $81.16 \%$ at $100 \mu \mathrm{g} \mathrm{mL}^{-1}$ UFRT.

Table 1: Mass balance of each fractionation during the process

\begin{tabular}{lcc}
\hline Description & Dry weight (g) & Dry weight/Initial solid weight (\%) \\
\hline Initial pinto bean powder & $198 \pm 4$ & $122 \pm 3$ \\
Centrifuged wet cake & $72 \pm 2$ & 37 \\
Centrifuged supernatants & $34 \pm 2$ & $17(47.22)^{*}$ \\
UFRT & $8 \pm 2$ & $4(11.11)^{*}$ \\
NFRT & $32 \pm 3$
\end{tabular}

Solid output/input ratio $=0.99$, Data are expressed as Mean \pm SD. $(n=3) .{ }^{*}$ Dry weight/centrifuged supernatants weight $(\%)$

Table 2: Proximate compositional analysis of pinto bean fractions

\begin{tabular}{|c|c|c|c|c|c|}
\hline Dry base (\%) & Pinto bean powder & Centrifuged wet cake & UFRT & NFRT & NFPE \\
\hline Protein & $23.50 \pm 0.07^{a}$ & $31.75 \pm 2.19^{b}$ & $59.92 \pm 2.81^{c}$ & $2.12 \pm 1.91^{d}$ & $2.31 \pm 1.43^{d}$ \\
\hline Fat & $3.24 \pm 0.15^{\mathrm{ab}}$ & $3.92 \pm 0.35^{\mathrm{a}}$ & $2.73 \pm 1.32^{b}$ & $2.32 \pm 1.21^{b}$ & $2.03 \pm 0.45^{b}$ \\
\hline Ash & $1.81 \pm 0.13^{\mathrm{a}}$ & $1.39 \pm 1.04^{b}$ & $1.12 \pm 0.71^{b}$ & $1.24 \pm 1.01^{\mathrm{b}}$ & $38.34 \pm 2.62^{b}$ \\
\hline *Simple sugars & $24.11 \pm 2.71^{a}$ & $11.99 \pm 4.32^{b}$ & $2.13 \pm 0.35^{c}$ & $8.21 \pm 1.43^{d}$ & $51.65 \pm 5.39^{e}$ \\
\hline \#Carbohydrates and others & $71.45 \pm 2.71^{\mathrm{a}}$ & $62.94 \pm 3.61^{b}$ & $36.23 \pm 5.21^{c}$ & $94.32 \pm 5.26^{\mathrm{cd}}$ & $57.32 \pm 2.24^{d}$ \\
\hline Dietary fiber & $23.80 \pm 1.12^{\mathrm{a}}$ & $32.30 \pm 3.92^{b}$ & $3.92 \pm 1.21^{\mathrm{c}}$ & $2.09 \pm 0.92^{\mathrm{cd}}$ & $1.98 \pm 0.62^{\mathrm{d}}$ \\
\hline
\end{tabular}

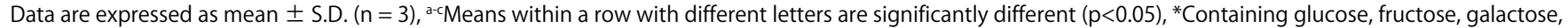
sucrose, maltose, "Including also the bioactive compounds such as polyphenols

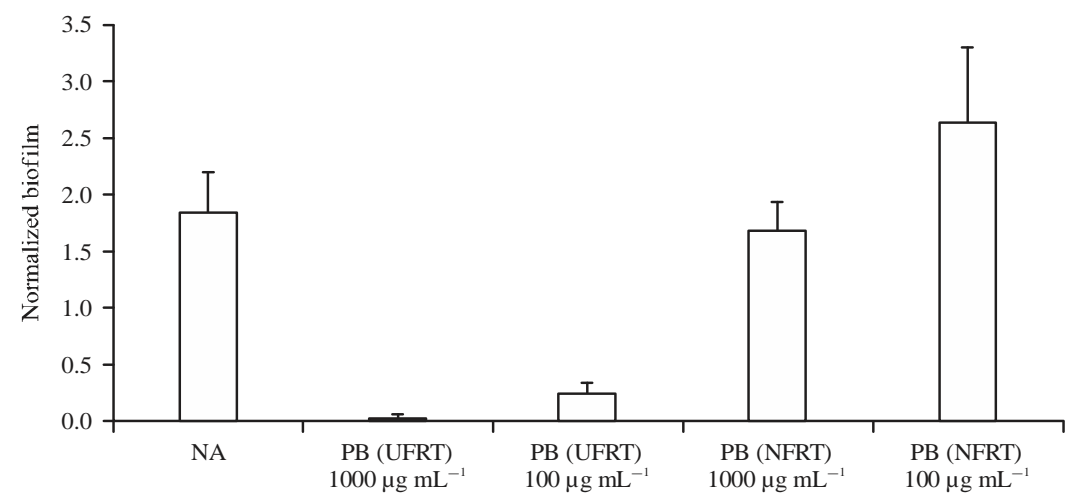

Fig. 2: Biofilm formation of Listeria monocytogenes in the presence of pinto bean UFRT and NFRT. Biofilms of L. monocytogenes formed in the MG9 medium for $24 \mathrm{~h}$ at $37^{\circ} \mathrm{C}$ with/without pinto bean (PB) UFRT and NFRT (100 and $1000 \mathrm{mg} \mathrm{mL}^{-1}$ ). Biofilm formation was normalized by dividing total biofilms $\left(\mathrm{OD}_{540 \mathrm{~nm}}\right)$ by cell growth $\left(\mathrm{OD}_{600 \mathrm{~nm}}\right)$

The error bar indicates the standard deviation of six replicates from two independent cultures 


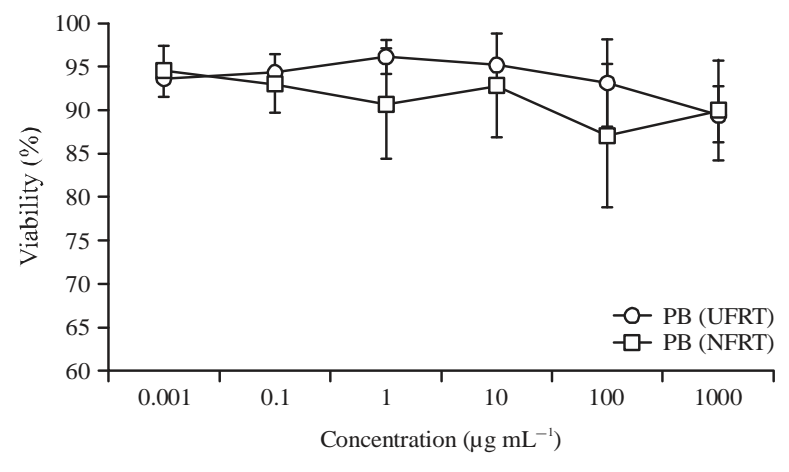

Fig. 3: Ovarian A2780 cancer cell viability test

The polyphenol-rich fraction from NFRT was not shown to significantly reduce the biofilm formation. The ovarian A2780 cancer cell viability was not significantly affected $(p<0.05)$ by pinto bean UFRT and NFRT (0.001-1,000 $\mu \mathrm{g} \mathrm{mL}^{-1}$ dosing rate) treatment (Fig. 3). The slight reduction of cancer cell viability was observed in NFRT but was not significant.

\section{DISCUSSION}

Extraction of bioactive compounds. Lectins are found in many plants such as beans and reported various health benefits ${ }^{26,27}$. Typically, lectins are isolated by precipitation methods using acids (e.g., acetic acid used by Naeem et al. ${ }^{28}$ ), organic solvents (e.g., acetone used by Medeiros et a/.29) or salts (e.g., ammonium sulfate). Then it is purified with various chromatographic methods such as affinity chromatography, ionic exchange chromatography, hydrophobic interaction chromatography and gel filtration ${ }^{27,30}$. Whereas, polyphenols traditionally are extracted with solvent-based treatment which gives a higher yield, however, it has limited human consumption due to the toxicity from harmful solvent ${ }^{31}$. Therefore, the conventional production methods of lectins and polyphenols are considered to have a high cost and is a hazardous process. In order to improve these backwards, lectin-rich and polyphenol-rich fraction were extracted through acid treatment followed by membrane filtration which was developed in this study as a safety, economic and scalable promising method for purifying lectins and polyphenols from the pinto bean. Membrane technology has been widely used to separate and concentrate from two liquids differ in their molecular size. This technology has become gradually attractive last decades because of its environmental friendly process, low energy consumption, high efficiency of separation and the improved final product quality 32 .
According to Tan et al.', typical pinto bean protein showed the minimum solubility into the $\mathrm{pH}$ range from 4.0-5.5 which is due to their isoelectric $\mathrm{pH}$ and the net charge will be little or zero. While $\mathrm{pH}$ values lower than 3 and higher than 6 , the protein solubility was reached the almost $100 \%$. Electrostatic repulsive forces among the proteins were reduced and led to protein precipitation with the $\mathrm{pH}^{33} 4.0-5.5$. However, lectins are proteins which possess at least at one non-catalytic domain that binds reversibly to specific carbohydrates and has a unique soluble characteristic compared to other normal proteins. On the contrary to typical proteins, lectins were able to be extracted with the $\mathrm{pH}^{30} 4.3-4.6$ and thus at this $\mathrm{pH}$ range, only lectins are able to become a soluble state among proteins which may bind to soluble mono or oligosaccharides and consequently lectins are able to be separated using membrane technology, not using a precipitation method. Moreover, the acid condition is able to increase the affinity of polyphenols which assistance to extraction. In this study, the $\mathrm{pH} 4.3$ was adjusted to the pinto bean solution and filtered (UF and NF) according to their respective molecular sizes (lectin-rich fraction from UFRT, polyphenol-rich fraction from NFRT). Dietary fiber and aggregated proteins should be insolubilized with the acid condition.

According to Wong et al. ${ }^{34}$, the molecular mass of the homodimeric lectin from pinto beans was $62 \mathrm{kDa}$ and that of each of its subunits was $31 \mathrm{kDa}$ which was stable with the $\mathrm{pH}$ 3-12 and $0-70^{\circ} \mathrm{C}$. Therefore, the UF system (5K MWCO) was able to retentate all extracted lectin fraction. According Ye et al. ${ }^{2}$, about $27.5 \mathrm{mg}$ of purified lectins were produced from $100 \mathrm{~g}$ red kidney bean using Affi-gel blue gel and CM-Sepharose. They obtained $5.29 \mathrm{~g}$ lectin-rich crude extracted protein fraction with Tris-HCL buffer treatment. Whereas about $10 \mathrm{~g}$ lectin-rich protein fraction was produced from $100 \mathrm{~g}$ pinto bean in this study. Moreover, it can be estimated by the significant amount of polyphenols extracted which was supported by the results of low content of simple sugars and dietary fiber in NFRT solution. Polyphenols molecular weight is typically between ${ }^{35}$ 500-4,000 Da. Therefore, the NF system (150-300 Da MWCO) was able to retentate polyphenols. These results supported that the acid treatment and membrane technology could be promising methods to extract the lectins and polyphenols from the pinto bean.

The inhibition of L. monocytogenes biofilm formation and ovarian cancer cell. The lectin-rich fraction from UFRT was able to significantly reduce the biofilm formation. Pinto bean lectin was identified as a galactose specify and thermostable 
up ${ }^{2,36}$ to $70^{\circ} \mathrm{C}$. Typically, antibacterial activity of lectins is explained by interaction with peptidoglycan, lipopolysaccharides and other molecules present in the cell wall of micro-organisms, interfering with blocking interaction sites with host cells preventing cell growth and viability ${ }^{37-39}$. However, bacterial biofilms show the totally different mechanisms compared to individual bacteria. There are multicellular communities enclosed in a self-produced extracellular polymeric matrix which are unable to be deeply penetrated by antibacterial molecules into the biofilm. Furthermore, bacterial cells are able to express resistance mechanisms making them recalcitrant under antibiotic treatment condition ${ }^{40}$. The polyphenol-rich fraction from NFRT was not shown to significantly reduce the biofilm formation which may be due to the low antimicrobial activity of pinto bean polyphenols and high oligosaccharides content. Polyphenols are secondary metabolites compounds in the plant which have important roles as defenses against plant pathogens. Its antimicrobial activity, especially flavan-3-ols, flavanols and tannins have been studied over the last decades and on several bacterial species, such as Vibrio, Streptococcus, Campylobacter, Clostridium, Escherichia coli and Candida. However, L. monocytogenes has not been significantly affected by pinto bean polyphenols. Some phenolic acids, non flavonoid compounds such as gallic, caffeic and ferulic acids showed the antimicrobial activity ${ }^{41}$, but not as significantly because of their low contents in pinto bean.

The ovarian cancer cell viability was not significantly affected by UFRT and NFRT. Typically, plant lectins have been considered alternative therapeutic agents due to their anticancer properties in vivo and in vitro clinical studies ${ }^{42,43}$. For that reason, drug delivery systems strategies have been continuously increased to the bioavailability of antitumor lectins ${ }^{44-46}$. The anticancer mechanisms of lectins are generally initiated by interaction with specific receptors on the cancer cell membrane and then the lectins can be internalized through endocytosis which induces the activation of signaling pathways related to cell death ${ }^{47,48}$. However, pinto bean lectin is interestingly devoid of antiproliferative activity to the leukemia cells $s^{34,49}$. The antiproliferative activity should depend on the carbohydrate binding activity of lectins. The binding sites of pinto bean lectin, glucosamine-specific lectins, should be blocked by the sugar, thus hindering the interactions with the cells, resulting in the reduction of the anti-proliferative effect ${ }^{50}$. The anti-cancer activities are also highly associated with the presence of phenolic compounds as well as lectins ${ }^{16}$. In this study, however, the polyphenol-rich fraction from NFRT was not significantly affected by cancer cell viability. It should be due to the low polyphenols activity and high carbohydrates content which could become the nutrient sources for cell growth.

More research is needed to improve the polyphenols activity for inhibition of biofilm formation and ovarian cancer cell viability with further purification and concentration of NFRT in the future. The accurate measurements of lectin and polyphenol content in the fraction are also needed.

\section{CONCLUSION}

In this study, it applied a new approach to extract lectins and polyphenols rich fractions from the pinto bean using acid treatment and membrane technology. Based on the obtained results, it may be inferred that pinto bean lectin-rich fraction from UFRT is effective in significantly inhibiting biofilm development of L. monocytogenes. Therefore, pinto bean lectin may be able to serve as listeria anti-biofilm agents to the food industry.

\section{SIGNIFICANCE STATEMENT}

This study discovers the new approach to extract lectin rich fractions from the pinto bean using acid treatment and membrane technology that can be beneficial for inhibiting biofilm development of $L$. monocytogenes. These findings encourage further research to investigate the critical areas of listerial biofilm formation in food industry that many studies were not able to explore and understand.

\section{REFERENCES}

1. Tan, E.S., N. Ying-Yuan and C.Y. Gan, 2014. A comparative study of physicochemical characteristics and functionalities of pinto bean protein isolate (PBPI) against the Soybean Protein Isolate (SPI) after the extraction optimisation. Food Chem., 152: 447-455.

2. Ye, X.Y., T.B. Ng, P.W.K. Tsang and J. Wang, 2001. Isolation of a homodimeric lectin with antifungal and antiviral activities from red kidney bean (Phaseolus vulgaris) seeds. J. Protein Chem., 20: 367-375.

3. Yin, C., J.H. Wong and T.B. Ng, 2015. Isolation of a hemagglutinin with potent antiproliferative activity and a large antifungal defensin from Phaseolus vulgaris cv. Hokkaido Large Pinto beans. J. Agric. Food Chem., 63: 5439-5448.

4. Ojeda, A.G., K. Wrobel, A.R.C. Escobosa, J.C.T. Elguera, M.E. Garay-Sevilla and K. Wrobel, 2015. Molybdenum and copper in four varieties of common bean (Phaseolus vulgaris): New data of potential utility in designing healthy diet for diabetic patients. Biol. Trace Element Res., 163: 244-254. 
5. Hamed, E.S., E.A. Ibrahim and S.M. Mounir, 2017. Antimicrobial activities of lectins extracted from some cultivars of Phaseolus vulgaris seeds. J. Microb. Biochem. Technol., 9: 109-116.

6. Chrispeels, M.J. and N.V. Raikhel, 1991. Lectins, lectin genes and their role in plant defense. Plant Cell., 3: 1-9.

7. Weder, J.K.P., L. Telek, M. Vozari-Hampe and H.S. Saini, 1997. Antinutritional factors in anasazi and other pinto beans (Phaseolus vulgaris L.). Plant Foods Hum. Nutr., 51: 85-98.

8. Mager, M.D., V. LaPointe and M.M. Stevens, 2011. Exploring and exploiting chemistry at the cell surface. Nature Chem., 3: 582-589.

9. Gupta, P., S. Sarkar, B. Das, S. Bhattacharjee and P. Tribedi, 2016. Biofilm, pathogenesis and prevention-A journey to break the wall: A review. Arch. Microbiol., 198: 1-15.

10. Wong, J.H. and T.B. Ng, 2003. Purification of a trypsin-stable lectin with antiproliferative and HIV-1 reverse transcriptase inhibitory activity. Biochem. Biophys. Res. Commun., 301: 545-550.

11. Ganesan, K. and B. Xu, 2017. A critical review on polyphenols and health benefits of black soybeans. Nutrients, Vol. 9. 10.3390/nu9050455.

12. Cheynier, V., 2005. Polyphenols in foods are more complex than often thought. Am. J. Clin. Nutr., 81: 223S-229S.

13. Beninger, C.W. and G.L. Hosfield, 2003. Antioxidant activity of extracts, condensed tannin fractions and pure flavonoids from Phaseolus vulgaris L. seed coat color genotypes. J. Agric. Food Chem., 51: 7879-7883.

14. Beninger, C.W., L. Gu, R.L. Prior, D.C. Junk, A. Vandenberg and K.E. Bett, 2005. Changes in polyphenols of the seed coat during the after-darkening process in pinto beans (Phaseolus vulgaris L.). J. Agric. Food Chem., 53: 7777-7782.

15. Akillioglu, H.G. and S. Karakaya, 2010. Changes in total phenols, total flavonoids and antioxidant activities of common beans and pinto beans after soaking, cooking and in vitro digestion process. Food Sci. Biotechnol., 19: 633-639.

16. Cardador-Martinez, A., E. Castano-Tostado and G. Loarca-Pina, 2002. Antimutagenic activity of natural phenolic compounds present in the common bean (Phaseolus vulgaris) against aflatoxin B1. Food Addit. Contam., 19: 62-69.

17. Colagiorgi, A., P. Di Ciccio, E. Zanardi, S. Ghidini and A. lanieri, 2016. A look inside the Listeria monocytogenes biofilms extracellular matrix. Microorganisms, Vol. 4. 10.3390/microorganisms4030022.

18. Di Bonaventura, G., R. Piccolomini, D. Paludi, V. D'Orio, A. Vergara, M. Conter and A. lanieri, 2008. Influence of temperature on biofilm formation by Listeria monocytogenes on various food contact surfaces: Relationship with motility and cell surface hydrophobicity. J. Applied Microbiol., 104: 1552-1561.

19. Bai, A.J. and V.R. Rai, 2011. Bacterial quorum sensing and food industry. Comprehen. Rev. Food Sci. Food Saf., 10: 183-193.
20. Tremoulet, F., O. Duche, A. Namane, B. Martinie, European Listeria Genome Consortium and J.C. Labadie, 2000. Comparison of protein patterns of Listeria monocytogenes grown in biofilm or in planktonic mode by proteomic analysis. FEMS Microbiol. Lett., 210: 25-31.

21. Hall-Stoodley, L., J.W. Costerton and P. Stoodley, 2004. Bacterial biofilms: From the natural environment to infectious diseases. Nat. Rev. Microbiol., 2: 95-108.

22. Carpentier, B. and O.Cerf, 2011. Review-Persistence of Listeria monocytogenes in food industry equipment and premises. Int. J. Food Microbiol., 145: 1-8.

23. AOAC., 2000. Official Methods of Analysis. 17th Edn., Association of Official Analytical Chemist, Washington, DC., USA.

24. Hong, S.H., J. Lee and T.K. Wood, 2010. Engineering global regulator Hha of Escherichia colito control biofilm dispersal. Microbial Biotechnol., 3: 717-728.

25. Fletcher, M., 1977. The effects of culture concentration and age, time and temperature on bacterial attachment to polystyrene. Can. J. Microbiol., 23: 1-6.

26. Islam, B., S.N. Khan, A. Naeem, V. Sharma and A.U. Khan, 2009. Novel effect of plant lectins on the inhibition of Streptococcus mutans biofilm formation on saliva coated surface. J. Applied Microbiol., 106: 1682-1689.

27. Lam, S.K. and T.B. Ng, 2011. Lectins: Production and practical applications. Applied Microbiol. Biotechnol., 89: 45-55.

28. Naeem, A., S. Haque and R.H. Khan, 2007. Purification and characterization of a novel $\beta$-D-galactosides-specific lectin from Clitoria ternatea. Protein J., 26: 403-413.

29. Medeiros, D.S., T.L. Medeiros, J.K.C. Ribeiro, N.K.V. Monteiro and L. Migliolo et al., 2010. A lactose specific lectin from the sponge Cinachyrella apion: Purification, characterization, $\mathrm{N}$-terminal sequences alignment and agglutinating activity on Leishmania promastigotes. Comp. Biochem. Physiol. Part B: Biochemis. Molecul. Biol., 155: 211-216.

30. Sattsangi, P.D., S. Sattsangi and H.H. Grossman, 1982. Isolation of soybean agglutinin (SBA) from soy meal. J. Chem. Edu., 59: 977-979.

31. Pasrija, D. and C. Anandharamakrishnan, 2015. Techniques for extraction of green tea polyphenols: A review. Food Bioprocess Technol., 89: 935-950.

32. Lee, Y.J., 2015. Manufacturing soy-protein concentrates and isolates by membrane technology. Int. J. Agric. Innov. Res., 3: $1150-1158$.

33. Singh, N., M. Kaur and K.S. Sandhu, 2005. Physicochemical and functional properties of freeze-dried and oven dried corn gluten meals. Drying Technol., 23: 975-988.

34. Wong, J.H., C.C. Wong and T.B. Ng, 2006. Purification and characterization of a galactose-specific lectin with mitogenic activity from pinto beans. Biochim. Biophys. Acta, 1760: 808-813. 
35. Haslam, E. and Y. Cai, 1994. Plant polyphenols (vegetable tannins): Gallic acid metabolism. Natural Prod. Rep., 11:41-66.

36. Wong, J.H. and T.B. Ng, 2005. A homotetrameric agglutinin with antiproliferative and mitogenic activities from haricot beans. J. Chromatogr. B, 828: 130-135.

37. Silva, P.M., T.H. Napoleao, L.C. Silva, D.T. Fortes and T.A. Lima et al., 2016. The juicy sarcotesta of Punica granatum contains a lectin that affects growth, survival as well as adherence and invasive capacities of human pathogenic bacteria. J. Funct. Foods, 27: 695-702.

38. Iordache, F., M. Ionita, L.I. Mitrea, C. Fafaneata and A. Pop, 2015. Antimicrobial and antiparasitic activity of lectins. Curr. Pharm. Biotechnol., 16: 152-161.

39. Fang, Z.Y., D. Li, X.J. Li, X. Zhang, Y.T. Zhu, W.W. Li and Q. Wang, 2016. A single CRD C-type lectin from Eriocheir sinensis (EsLeCB) with microbial-binding, antibacterial prophenoloxidase activation and hem-encapsulation activities. Fish Shellfish Immunol., 50: 175-190.

40. De la Fuente-Nunez, C., F. Reffuveille, L. Fernandez and R.E. Hancock, 2013. Bacterial biofilm development as a multicellular adaptation: Antibiotic resistance and new therapeutic strategies. Curr. Opin. Microbiol., 16: 580-589.

41. Daglia, M., 2012. Polyphenols as antimicrobial agents. Curr. Opin. Biotechnol., 23: 174-181.

42. De Mejia, E.G. and V.I. Prisecaru, 2005. Lectins as bioactive plant proteins: A potential in cancer treatment. Crit. Rev. Food Sci. Nutr., 45: 425-445.
43. Liu, B., H.J. Bian and J.K. Bao, 2010. Plant lectins: Potential antineoplastic drugs from bench to clinic. Cancer Lett., 287: 1-12.

44. Andrade, C.A., M.T. Correia, L.C. Coelho, S.C. Nascimento and N.S. Santos-Magalhaes, 2004. Antitumor activity of Cratylia mollis lectin encapsulated into liposomes. Int. J. Pharm., 278: 435-445.

45. Bonifacio, B.V., P.B. da Silva, M.A. dos Santos Ramos, K.M.S. Negri, T.M. Bauab and M. Chorilli, 2014. Nanotechnology-based drug delivery systems and herbal medicines: A review. Int. J. Nanomed., 9: 1-15.

46. Han, S.Y., C.E. Hong, H.G. Kim and S.Y. Lyu, 2015. Anti-cancer effects of enteric-coated polymers containing mistletoe lectin in murine melanoma cells in vitro and in vivo. Mol. Cell. Biochem., 408: 73-87.

47. Yau, T., X. Dan, C. Ng and T. Ng, 2015. Lectins with potential for anti-cancer therapy. Molecules, 20: 3791-3810.

48. Gabor, F., U. Klausegger and M. Wirth, 2001. The interaction between wheat germ agglutinin and other plant lectins with prostate cancer cells Du-145. Int. J. Pharm., 221: 35-47.

49. Iwama, M., Y. Ogawa, N. Sasaki, K. Nitta and Y. Takayanagi et al., 2001. Effect of modification of the carboxyl groups of the sialic acid binding lectin from bullfrog (Rana catesbeiana) oocyte on anti-tumor activity. Biol. Pharm. Bull., 24: 978-981.

50. Chan, Y.S., L. Xia and T.B. Ng, 2016. White kidney bean lectin exerts anti-proliferative and apoptotic effects on cancer cells. Int. J. Biol. Macromol., 85: 335-345. 